\section{New drug for allergic rhinitis}

Aust Prescr 2016;39:192

http://dx.doi.org/10.18773/austprescr.2016.088

I read the new drug comment on dust mite allergen extract for allergic rhinitis with interest.' I am not sure why this product is being marketed or even discussed if the only benefit is a small reduction in symptoms but insufficient effect to reduce the use of rescue medications. The effect on IgE concentrations is interesting, but obviously fails to translate into clinically (and financially) relevant benefits. There are also unwelcome and possibly distressing adverse effects.

It will not be going into my armamentarium just yet, unless there is something of major importance I am missing. I think not.

Jan Sheringham

Corlis fellow

Advocacy, continuing education and training

RACGP Victoria

\section{REFERENCE}

1. Dust mite allergen extract. Aust Prescr 2016;39:184-5. http://dx.doi.org/10.18773/austprescr.2016.077
The Editorial Executive Committee of Australian Prescriber comments:

Thank you for your letter. The purpose of the New Drugs section is to provide prescribers with independent information on new chemical entities marketed in Australia. These short summaries on how the drug works, the evidence for its approval and its adverse effects aim to help prescribers make their own decisions when deciding whether or not to prescribe a new drug.

As mentioned in the preamble for each drug comment, the information should be regarded as preliminary. In this instance, the comment was based on limited published data as is often the case. The Editorial Executive Committee believes that comments made in good faith at an early stage may still be of value to prescribers. 